Research Article

\title{
Deterioration Regularity of Sodium Sulfate Solution Attack on Cemented Coal Gangue-Fly Ash Backfill under Drying-Wetting Cycles
}

\author{
Shaojie Chen, Zhen Zhang ${ }^{D}$, Dawei Yin $\mathbb{D}^{D}$, and Junbiao Ma \\ State Key Laboratory of Mine Disaster Prevention and Control, Shandong University of Science and Technology, \\ Qingdao 266590, China \\ Correspondence should be addressed to Zhen Zhang; 2954163563@qq.com and Dawei Yin; 949251142@qq.com
}

Received 17 August 2020; Revised 11 September 2020; Accepted 20 September 2020; Published 30 September 2020

Academic Editor: Chun Zhu

Copyright ( 2020 Shaojie Chen et al. This is an open access article distributed under the Creative Commons Attribution License, which permits unrestricted use, distribution, and reproduction in any medium, provided the original work is properly cited.

To research the properties of cemented coal gangue-fly ash backfill (CGFB) exposed to different concentrations of sodium sulfate solutions under drying-wetting cycles, the mass changes, uniaxial compressive strengths, sulfate ion contents at different depths, and microstructures of CGFB samples were measured in this study. The results show that the CGFB samples were damaged by salt crystallization in the dry state and attacked by the expansive products in the wet state. The sulfate ion contents in CGFB samples increased with the sulfate concentrations and drying-wetting cycles and decreased from the surface to the inside of the samples. The damage process of CGFB samples evolved from the surface to the inside. In the early stage of corrosion, sulfate ions adsorbed to the surface of CGFB samples and consumed nonhydrated particles to form acicular ettringite and other products that filled the material pores. For this stage, the driving force of sulfate ions to enter into the CGFB samples was the highest for the samples immersed in $15 \%$ sodium sulfate solution, and the masses and strengths increased the fastest. As the drying-wetting cycles continued, the nonhydrated particles inside the samples were nearly completely hydrated, and the samples were constantly damaged by salt crystallization and dissolution. The corrosion ions entered into the samples and consumed portlandite to produce a large amount of prismatic ettringite and aggravated the internal corrosion of CGFB samples. At the fifteenth drying-wetting cycle, the higher the salt concentration of the immersion solution was, the faster the masses and the strengths of CGFB samples decreased. Moreover, the surface spalling and failure of CGFB samples were more severe.

\section{Introduction}

Coal takes the dominant position in China's energy market and energy consumption structure [1]. While consuming coal resources, it also faces a series of problems, such as solid waste pollution, surface subsidence, and slope failures caused by mining activities [2]. Paste filling is an ideal approach to control surface subsidence and protect the mining environment. The technique uses coal gangue, fly ash, and other solid wastes near coal mines as the main raw materials to process paste slurry, which is then transported to the goaf through a pipeline [3-5]. The properties of cemented coal gangue-fly ash backfill (CGFB) are the basis of paste filling to determine the effect of controlling ground subsidence. However, the level of underground water in coal mines varies with rainfall, seasons, reservoir storage and drainage, etc., and the environment of the goaf would be either dry or wet. In addition, mine water often contains sulfates and other salts $[6,7]$. The CGFB would suffer from the effect of drying-wetting cycles of mine water, which in turn would influence the safety and stability of the goaf. Therefore, it is of great significance to study the performance of CGFB exposed to sulfate attack under the condition of drying-wetting cycles.

In recent years, many studies have shown the deterioration regularity of cement-based materials immersed in sulfate solutions. Liu et al. [8-10] studied the influence of high sulfate solutions on the properties of cement-based materials and found that the strengths of the materials improved in the early stage of immersion and decreased with 
immersion ages. Sun et al. [11] found that the creep deformation of filling paste would be intensified as the corrosion continued. Fall and Pokharel $[12,13]$ studied the coupled effect of sulfate and temperature on cement-paste backfill and found that this effect decreased or increased the hydraulic conductivity of cement-paste backfill. Yu et al. $[14,15]$ found that ettringite expansion was the root of paste deterioration when sulfate ions in pore solutions reached the critical value. Yao et al. [16] found that the presence of chloride in the composite solution led to acicular ettringite as the main corrosion product. When the cement-based materials were partially immersed in sulfate solutions, the sulfate ions would enter the materials through capillary adsorption, resulting in salt concentration solutions in the pores $[17,18]$. The material above the liquid level suffered physical erosion and the material below the liquid level could be damaged by chemical erosion [19-21].

Compared with the single damage of sulfate attack, the damage process of cement-based materials could be accelerated under sulfate attack of drying-wetting cycles [22]. In such a case, the concrete was affected by chemical erosion in the wet state $[23,24]$ and by physical erosion in the dry state [25-28]. Yuan et al. [29, 30] studied the failure process and microcosmic variation of concrete under sulfate attack of drying-wetting cycles by X-ray CT. Jiang and Niu [31] studied the effect of different types of sulfate solutions under drying-wetting cycles on concrete and found that the deterioration degree of concrete in a magnesium sulfate solution was more severe than in other sulfate solutions. Chen et al. [32, 33] studied the combined attack of chloride and sodium sulfate under drying-wetting cycles on concrete and found that the higher sulfate contents in combined solutions retarded the damage of concrete.

The above-mentioned researches are of great significance in understanding the deterioration regularity of CGFB exposed to the cyclic sulfate environment. Compared with other cement-based materials, the compositions and contents of CGFB are quite different, which may be more easily affected by this effect. However, there were few investigations on the deterioration regularity of CGFB under sulfate attack of drying-wetting cycles. Therefore, the mass changes, uniaxial compressive strengths, sulfate ion contents at different depths, and microstructures of CGFB under this effect were studied in this paper. In addition, the damage process of CGFB under sulfate attack of drying-wetting cycles was analyzed.

\section{Materials and Methods}

2.1. Raw Materials. In this investigation, four components were used for CGFB sample preparation: cement, fly ash, coal gangue, and water. The cement was the 42.5 slag Portland cement (Second Cement Plant, Yishui, Shandong Province), and the grade II fly ash was selected with a lightgray color (Huangdao Power Plant, Qingdao, Shandong Province). The coal gangue came from the solid waste produced in Daizhuang Coal Mine (Zibo Mining Group, Shandong Province) and was carried by secondary crushing. Most of the gangue was between 0.1 and $13.2 \mathrm{~mm}$, and only a few of them reach $20-25 \mathrm{~mm}$. Laboratory tap water was selected for experiments. The sodium sulfate anhydrous used for the soaking solutions was of analytical purity (Chengdu Kelong Chemical Reagent Factory) with a sodium sulfate content of $\geq 99 \%$. The major chemical compositions of the cement, fly ash, and gangue are shown in Figure 1.

2.2. Sample Preparation. Previous investigations have indicated that a ratio of cement to fly ash to gangue of $1: 4: 6$ and solid mass fraction of $74 \%$ yields CGFB with the best performance [34, 35]. Therefore, the CGFB samples were prepared with this ratio. First, the materials were mixed in a cement-paste mixer (NJ-160, Yixuan Test Instrument Company, China) for approximately $8 \mathrm{~min}$. Subsequently, the well-stirred mixture was poured into a mold with a length $\times$ width $\times$ height $=70 \mathrm{~mm} \times 70 \mathrm{~mm} \times 70 \mathrm{~mm} \quad$ [36] Manual vibration was used to prevent bubbles in the samples. Finally, the samples were removed from the mold after $24 \mathrm{~h}$ and cured for $28 \mathrm{~d}$ in a curing box at $25^{\circ} \mathrm{C}$ and humidity of $80 \%$. The CGFB samples were trimmed with a stone-grinding machine, and the sides were mechanically sanded with fine emery paper before testing [37].

The drying-wetting cycle procedure is shown in Figure 2. The CGFB samples were dried in a heating and drying oven at $60^{\circ} \mathrm{C}$ for $6 \mathrm{~h}[25,38]$ and then cooled at $25^{\circ} \mathrm{C}$ for $3 \mathrm{~h}$; this was considered the 0th drying-wetting cycle. Subsequently, the CGFB samples were immersed in sodium sulfate solutions with different concentrations $(0 \%, 5 \%, 10 \%$, and $15 \%)$. After the samples were saturated for $36 \mathrm{~h}$, they were removed and cooled at $25^{\circ} \mathrm{C}$ for $3 \mathrm{~h}$. Finally, after drying at $60^{\circ} \mathrm{C}$ for $6 \mathrm{~h}$, the samples were again cooled at $25^{\circ} \mathrm{C}$ for another $3 \mathrm{~h}$. The process from immersion to drying and cooling was regarded as a single wetting-drying cycle. In this experiment, there were 15 cycles performed in total. During the soaking process, the container was sealed by a preservative film, and the solutions were refreshed every 3 cycles.

\subsection{Testing Methods}

2.3.1. Mass Change. The mass changes of CGFB samples at different corrosion ages were monitored as an important indicator of deterioration. The masses of the samples before $\left(M_{i}\right)$ and after $\left(M_{t}\right)$ immersion in sodium sulfate solutions with different concentrations were measured every 3 cycles on an electronic scale with a capacity of $500 \mathrm{~g}$ and an accuracy of $0.01 \mathrm{~g}$. Consequently, the mass change $\left(M_{c t}\right)$ was calculated as follows:

$$
M_{c t}=\frac{M_{i}-M_{t}}{M_{i}} \times 100 \% .
$$

2.3.2. Uniaxial Compressive Strength. Uniaxial compressive strength (UCS) was considered as one of the most important parameters for evaluating the mechanical characteristics of the sample $[39,40]$. In this study, an electronic (AG-X250, Shimadzu, Japan) universal testing machine was selected as the loading system [41]. A displacement loading method was 


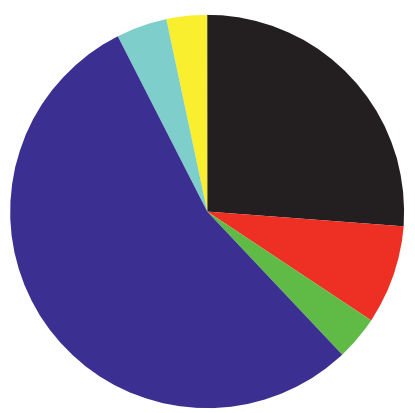

$\mathrm{CaO}-25.28 \%$

$\mathrm{SiO}_{2}-7.86 \%$

$\mathrm{Al}_{2} \mathrm{O}_{3}-3.51 \%$

- $\mathrm{Fe}_{2} \mathrm{O}_{3}-52.62 \%$

$\mathrm{MgO}-4.02 \%$

Other-3.21\%

(a)

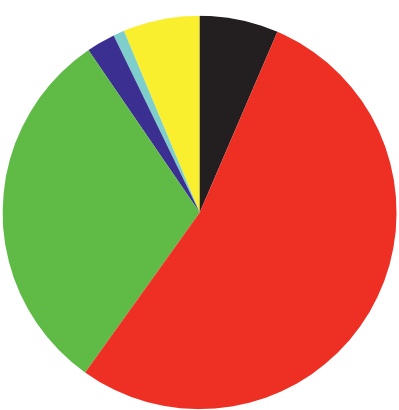

$\mathrm{CaO}-6.53 \%$

$\mathrm{SiO}_{2}-53.94 \%$

$\mathrm{Al}_{2} \mathrm{O}_{3}-30.91 \%$

$\mathrm{Fe}_{2} \mathrm{O}_{3}-2.38 \%$

$\mathrm{MgO}-0.92 \%$

Other-6.34\%

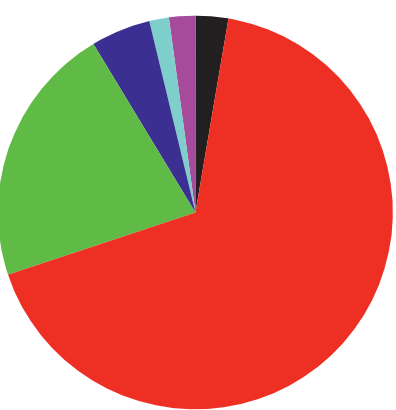

$\mathrm{CaO}-2.36 \%$

$\mathrm{SiO}_{2}-59.10 \%$

$\mathrm{Al}_{2} \mathrm{O}_{3}-18.90 \%$

$\mathrm{Fe}_{2} \mathrm{O}_{3}-4.30 \%$

$\mathrm{MgO}-1.41 \%$

$\mathrm{K}_{2} \mathrm{O}-1.89 \%$

(c)

FIgURe 1: Chemical compositions of raw materials: (a) cement, (b) fly ash, and (c) coal gangue.

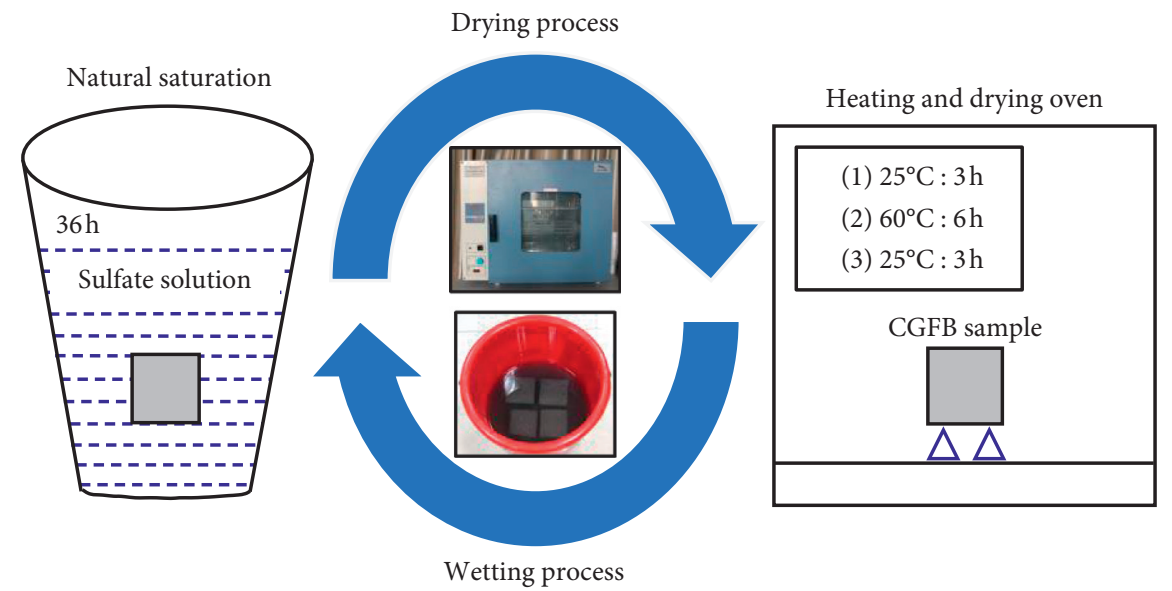

Figure 2: Schematic illustration of the cyclic drying-wetting treatment.

adopted in these tests at a loading rate of $0.01 \mathrm{~mm} / \mathrm{s}$. The residual strength ratio $(R)$ of the CGFB sample was calculated as follows [38]:

$$
R=\frac{f^{\mathrm{Attack}}}{f^{0}}
$$

where $f^{0}$ was the average UCS of CGFB samples at the standard curing age $(28 \mathrm{~d})$, which was $2.03 \mathrm{MPa} ; f^{\text {Attack }}$ were the UCSs of CGFB samples under sulfate attack of dryingwetting cycles.

2.3.3. Sulfate Ion Contents of CGFB at Different Depths. To study the sulfate ion contents at different depths, a lowspeed diamond cutting machine (SYJ-150, Kejing AutoInstrument Company, China) was used to slice the CGFB samples at different corrosion ages into layers that were $5 \mathrm{~mm}$ in thickness. The slices were ground in a mortar and screened with a $0.075 \mathrm{~mm}$ sieve after drying for $3 \mathrm{~d}$. Subsequently, the sulfate ion contents of powder samples were tested by chemical titration according to the Chinese National Standard GB/T176-2017 [42, 43]. The sulfate ion contents $\left(W_{\mathrm{SO}_{4}^{-2}}\right)$ in CGFB samples were calculated as follows [38]:

$$
W_{\mathrm{SO}_{4}{ }^{2-}}=1.2 \times \frac{0.343 \times\left(m_{2}-m_{1}\right)}{m} \times 100 \%,
$$

where $m_{1}$ is the mass of the crucible, $m_{2}$ is the total mass of the precipitate and crucible, and $m$ is the mass of the CGFB sample powder. The coefficients of 0.343 and 1.2 correspond to the conversion of $\mathrm{BaSO}_{4}$ to $\mathrm{SO}_{3}$ and $\mathrm{SO}_{3}$ to $\mathrm{SO}_{4}{ }^{2-}$, respectively.

2.3.4. Microstructures. A high- and low-vacuum SEM (JSM$6510 \mathrm{LV}$, Jeol, Japan) were used to study the microstructures and morphology of the corrosion products. The high-vacuum resolution was $3 \mathrm{~nm}(30 \mathrm{kV}) / 8 \mathrm{~nm}(3 \mathrm{kV}) / 15 \mathrm{~nm}(1 \mathrm{kV})$, and the low-vacuum resolution was $4.0 \mathrm{~nm}(30 \mathrm{kV})$. The specimens were cut from the CGFB surface and interior at 
selected corrosion ages, and the sampling depths of CGFB were $0-5 \mathrm{~mm}$ and $10-15 \mathrm{~mm}$, respectively. The specimens were immersed in an alcoholic solution to terminate hydration and dried before testing. A layer of conductive metal was then sprayed onto the specimens' surface, and the internal structure of specimens was observed.

XRD was used to analyze the mineral compositions of the corrosion products at different corrosion ages. XRD analysis was performed using a diffractometer $(\mathrm{D} / \max 2500$ $\mathrm{PC}, \mathrm{Cu} \mathrm{K} \alpha$ radiation, $2 \theta=10^{\circ}-80^{\circ}$ ) with an operating voltage of $40 \mathrm{kV}$, emission current of $40 \mathrm{~mA}$, and step size of $0.02^{\circ}$.

\section{Results and Discussion}

\subsection{Macroscopic Performance of CGFB}

3.1.1. Surface Damage. The surface damage of the CGFB samples exposed to the cyclic sulfate environment is shown in Figure 3. In the early stage of corrosion, the corners of the CGFB samples peeled off and spread towards the middle, and this was mainly because of the expansion and contraction from water absorption and loss. In addition, CGFB samples generated white dot-like products at the corners (as shown in yellow-circled areas) after immersion in all sodium sulfate solutions except the $0 \%$ solution, which indicated that salt crystallization occurred on the surface. This was because of the rough surface of CGFB samples providing sites for the retention of sulfate ions. In the dry state, the sulfate ions in the pores easily reached supersaturation, leading to crystal growth. As the drying-wetting cycles continued, the salt crystallized on the surface of CGFB samples in the dry state and dissolved in the wet state. Subsequently, the sulfate ions invaded the interior of the CGFB samples and reacted with hydration products to form expansive products. This effect increased the surface damage and resulted in continuous peeling of the CGFB samples.

3.1.2. Mass Change. The mass changes of CGFB samples under sulfate attack of drying-wetting cycles are shown in Figure 4. The mass changes of CGFB samples can be divided into three stages: rapid decrease of mass ( $0-3$ cycles), stable increase of mass (3-9 cycles), and stable decrease of mass (9-15 cycles). At the third cycle, the masses of CGFB samples immersed in $0 \%, 5 \%, 10 \%$, and $15 \%$ sodium sulfate solutions decreased by $4.69 \%, 4.11 \%, 3.93 \%$, and $3.79 \%$, respectively. This was mainly caused by spalling of the sample's surface. At the sixth cycle, the masses of CGFB samples immersed in each sodium sulfate solution increased by $0.11 \%, 0.20 \%$, $0.35 \%$, and $0.37 \%$, respectively, compared with the masses at the third cycle. This was because the cement particles generated some cementitious substances after hydration. Furthermore, the hydration products absorbed water and filled the internal pores of CGFB samples, which increased the masses of the samples. Therefore, the masses of CGFB were affected by the cementitious substances and pore evolution of the samples [44]. At the ninth cycle, the masses of all CGFB samples increased except for the samples immersed in $0 \%$ sodium sulfate solution. This may be because the cement particles inside the paste were nearly completely hydrated, and the samples were constantly damaged by water absorption and loss. At the twelfth cycle, the masses of CGFB samples in each sodium sulfate solution decreased, with the masses of the samples in $15 \%$ sodium sulfate solution decreasing the most. This was mainly because the samples in $0 \%$ sodium sulfate solution were constantly damaged by water absorption and loss. In addition, the samples in sodium sulfate solutions produced a large number of corrosion products and they were constantly damaged by salt crystallization and dissolution. As the drying-wetting cycles continued, the masses of the CGFB samples continued to decline. At the fifteenth cycle, the masses of the CGFB samples immersed in each sodium sulfate solution decreased by $0.14 \%, 0.94 \%, 1.45 \%$, and $1.49 \%$, respectively, compared with the masses in the twelfth cycle. The masses of CGFB samples immersed in 15\% sodium sulfate solution decreased the most, while those of the CGFB samples immersed in $0 \%$ sodium sulfate solution decreased the least.

3.1.3. Uniaxial Compressive Strength. The changing regularity of uniaxial compressive strengths of the CGFB samples under sulfate attack of drying-wetting cycles is shown in Figure 5. With the increase in the number of drying-wetting cycles, the strengths of CGFB samples first increased and then decreased. At the third cycle, the residual strength ratios of the CGFB samples immersed in $0 \%, 5 \%, 10 \%$, and $15 \%$ sodium sulfate solutions were $0.96,1.11,1.15$, and 1.21 , respectively. The strengths of the CGFB samples increased to some extent in all sodium sulfate solutions aside from the samples in the $0 \%$ sodium sulfate solution. The latter was mainly because of spalling of the surface in the early stage of corrosion. At the sixth cycle, the residual strength ratios of CGFB samples in each sodium sulfate solution were 1.09, $1.31,1.36$, and 1.43 , respectively. The higher the concentration of sodium sulfate solution was, the faster the increase in the strengths of CGFB samples would be. As the ettringite filled the internal pores and grew radially, the crystal connections inside the paste increased. Simultaneously, the consumption of portlandite promoted the continuous hydration of cement particles to generate more cementitious materials, which improved the cementation between internal aggregates. At the ninth cycle, the residual strength ratios of CGFB samples in each sodium sulfate solution were $1.02,1.36,1.54$, and 1.46 , respectively. Unlike the other samples, the strengths of CGFB samples in the $0 \%$ sodium sulfate solution decreased and the strengths of samples in the $10 \%$ sodium sulfate solution increased the most in this cycle. The former may be because of the constant damage by water absorption and loss, and the latter was because the cement particles inside the paste were nearly completely hydrated and the samples were constantly damaged by salt crystallization and dissolution. Moreover, a higher concentration of sulfate solution led to a greater driving force acting on sulfate ions entering the CGFB samples. As the dryingwetting cycles continued, the strengths of the CGFB samples continued to decline. At the end of the drying-wetting cycle, the residual strength ratios of CGFB samples in each sodium 

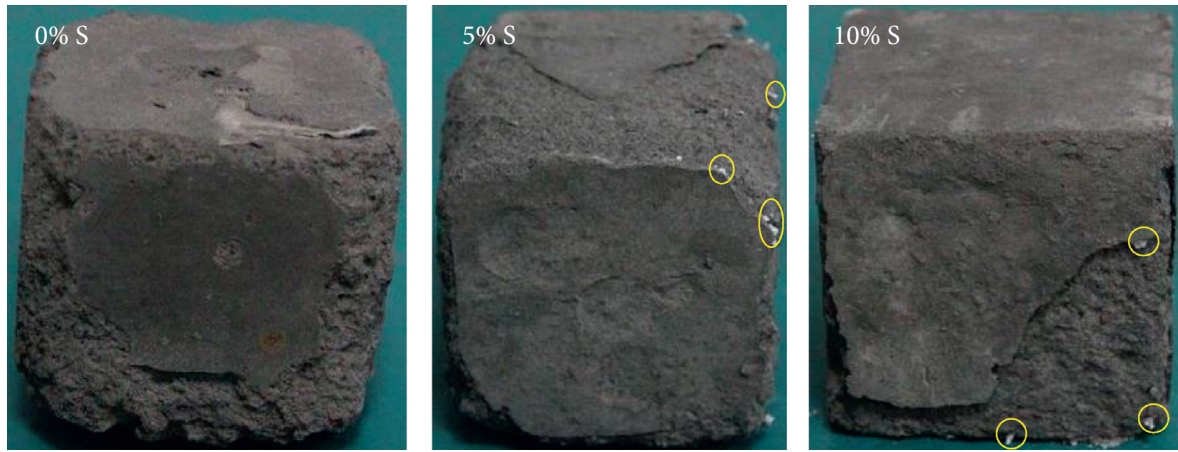

(a)
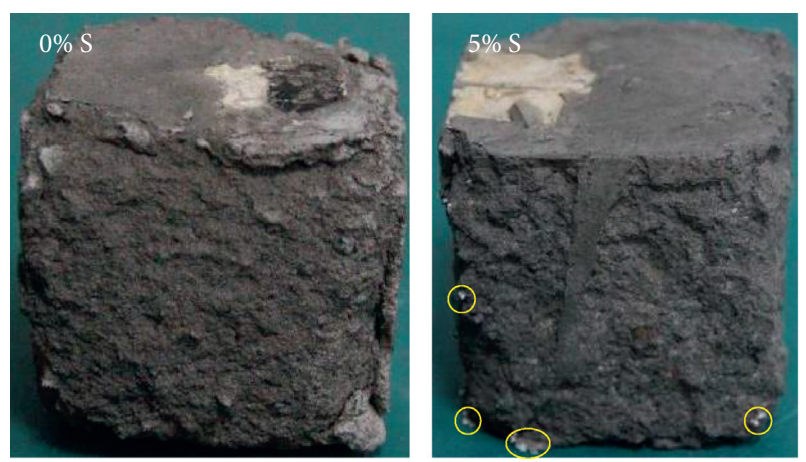
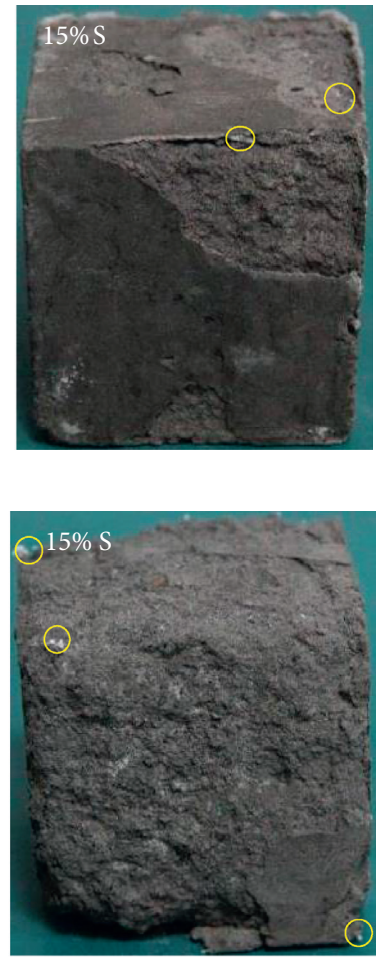

(b)

FIGURE 3: Surface damage of the CGFB samples immersed in 0-15\% sodium sulfate solutions at the (a) third and (b) fifteenth drying-wetting cycles.

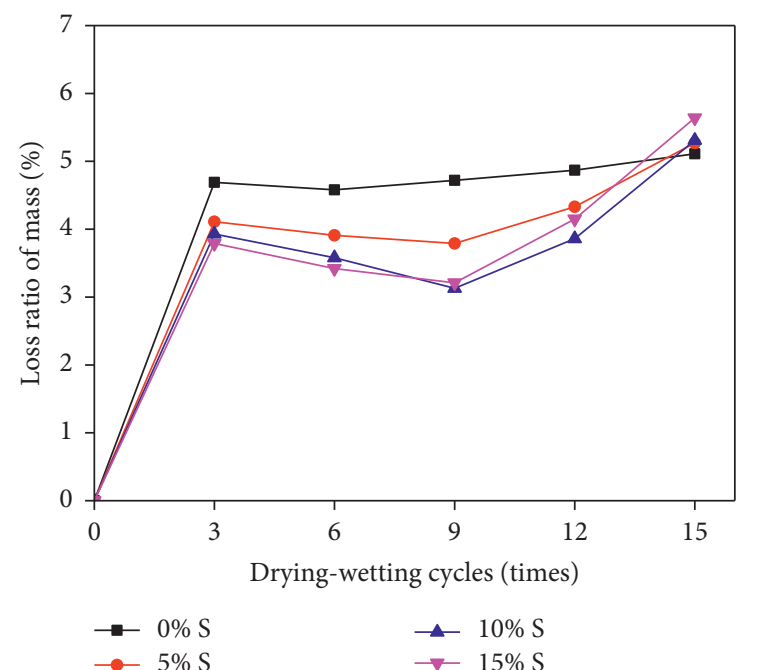

Figure 4: Mass changes of CGFB samples under sulfate attack of drying-wetting cycles.

sulfate solution were $0.81,0.76,0.71$, and 0.57 , respectively. A higher concentration of sodium sulfate solution led to a greater decrease in the strengths of CGFB samples.

3.1.4. Failure Characteristics. It can be clearly observed from Figure 6 that the CGFB samples exhibited the layered failure. Further, the geometrical trajectory of the fracture in CGFB

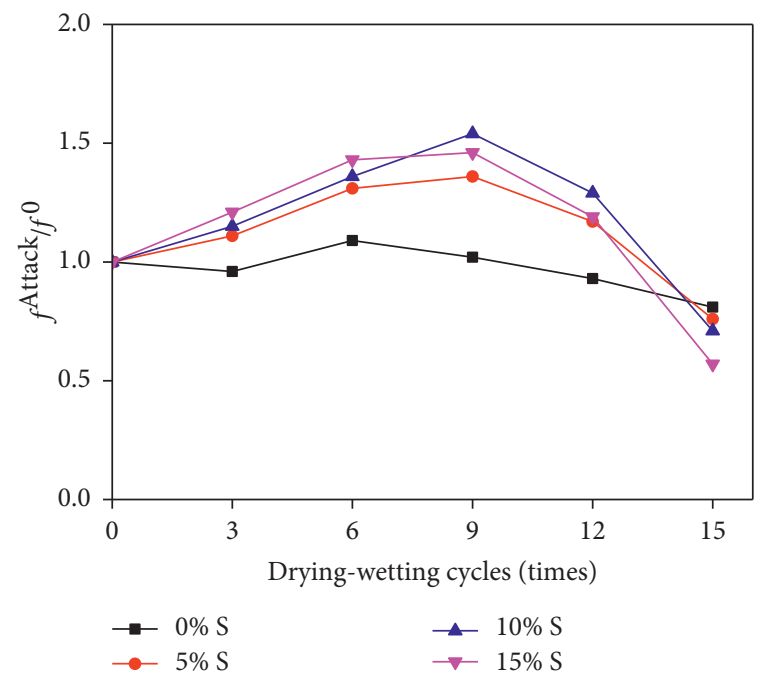

FIgURE 5: Residual strength ratios of CGFB samples under sulfate attack of drying-wetting cycles.

samples can be classified into two types, namely, the through fracture and the nonthrough fracture [45]. At the third cycle, the surface of the CGFB samples peeled off, and different forms of damage occurred under uniaxial compression. This was mainly due to the surface damage of CGFB from water absorption and loss. The CGFB samples immersed in the 0\% sodium sulfate solution had the most serious damage, while the CGFB samples immersed in the $15 \%$ sodium sulfate 

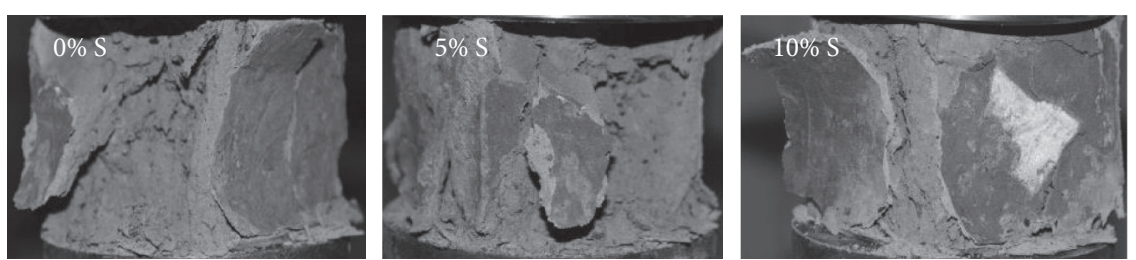

(a)
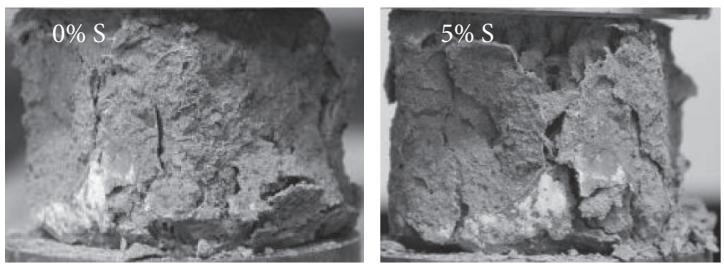
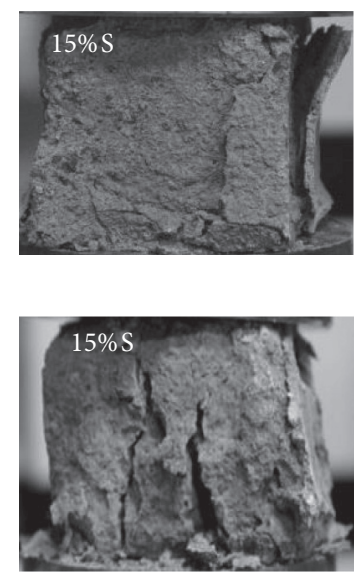

(b)

FIGURE 6: Failure characteristics of CGFB samples immersed in 0-15\% sodium sulfate solutions at the (a) third and (b) fifteenth dryingwetting cycles.

solution were relatively lightly damaged. At the fifteenth cycle, the CGFB samples were mainly in the form of cleavage, and the surface layers continued to peel. At this point, the CGFB samples immersed in the $0 \%$ sodium sulfate solution were relatively lightly damaged, while the CGFB samples immersed in other sodium sulfate solutions were more severely damaged.

\subsection{Microscopic Observation of CGFB}

3.2.1. Sulfate Ion Contents of CGFB at Different Depths. The sulfate ion contents at different depths of the CGFB samples under sulfate attack of drying-wetting cycles are presented in Figure 7. For the same drying-wetting cycle and concentration of sodium sulfate solution, the sulfate ion contents of CGFB samples decreased with depth. Moreover, for the same drying-wetting cycle and sampling depth, the sulfate ion contents of CGFB samples increased with the concentration of sodium sulfate solution. Additionally, for the same depth and salt solution concentration, the sulfate ion contents of CGFB samples increased with drying-wetting cycles. In the early stage of corrosion, due to the high sulfate ions in immersion solutions, sulfate ions were concentrated on the sample surface and the sulfate ion contents of the CGFB samples decreased with sampling depth. A higher concentration of erosion solution led to a greater driving force acting on sulfate ions entering the CGFB samples. The corrosion solution in CGFB pores would evaporate and crystallize in the dry state and produced pressure between the pore walls [26]. When CGFB samples were in the wet state, the crystals dissolved, and this plastic damage was difficult to recover. In addition, the accumulation of erosion products inside the paste aggravated internal damage and sulfate ions easily entered the CGFB samples.

3.2.2. SEM and XRD Analyses. The microstructures of the CGFB samples were studied by SEM and XRD after selected times under sulfate attack of drying-wetting cycles. Figure 8 shows the SEM images of the CGFB surface layers at the fifteenth drying-wetting cycle. The surface layers of CGFB samples immersed in $0 \%$ sodium sulfate solution had many pores because of severe spalling. However, fewer cracks were distributed on the surface, with only a few acicular ettringite crystals observed in the pores. For the samples immersed in $5 \%$ sodium sulfate solution, the crack width of the CGFB surface layer was larger, and ettringite was distributed in the crack depth. At a higher concentration of sodium sulfate solution, it is easier for sulfate ions to enter into the CGFB samples and affect the interface characteristics of the samples [46]. Therefore, the cracks on the surface of the CGFB samples widened and the erosion worsened. In addition, crack initiation and propagation are the important stages in the failure process of CGFB; the interaction between various heterogeneous substances would affect the internal pore structure and promote the generation of new cracks and the propagation of original cracks [47-51]. Nevertheless, there was no ettringite observed on the surface of CGFB samples immersed in $15 \%$ sodium sulfate, which may be caused by the consumption of portlandite and the unstable dissolution of ettringite.

Figure 9 shows the SEM images of the CGFB samples at the same depth eroded at different periods. At the third drying-wetting cycle, the hydrated calcium silicate $(\mathrm{C}-\mathrm{S}-\mathrm{H})$ gel accounted for the main body of strength, lamellar portlandite accumulated around the gel, acicular crystals grew in clusters, and no gypsum was observed in CGFB samples immersed in $0 \%$ sodium sulfate solution. With an increase in the concentration of sodium sulfate solution, the lamellar crystals grew alternately with ettringite that became smaller, the surface became smoother, and the microstructures became more compact. At the fifteenth dryingwetting cycle, the acicular ettringite was irregular in CGFB samples immersed in $0 \%$ sodium sulfate solution. The quantity of prismatic ettringite increased, while that of the acicular ettringite decreased in the samples immersed in $5-15 \%$ sodium sulfate solutions. Furthermore, the lamellar 


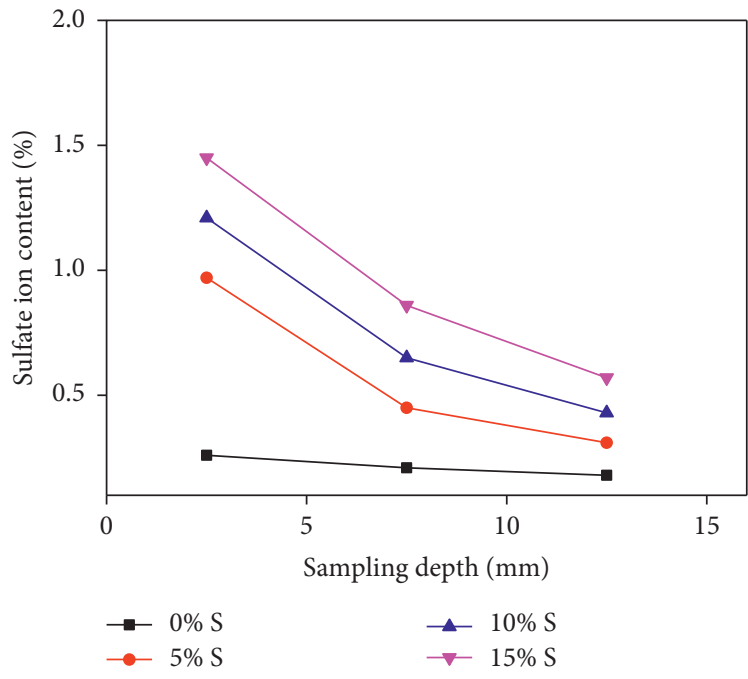

(a)

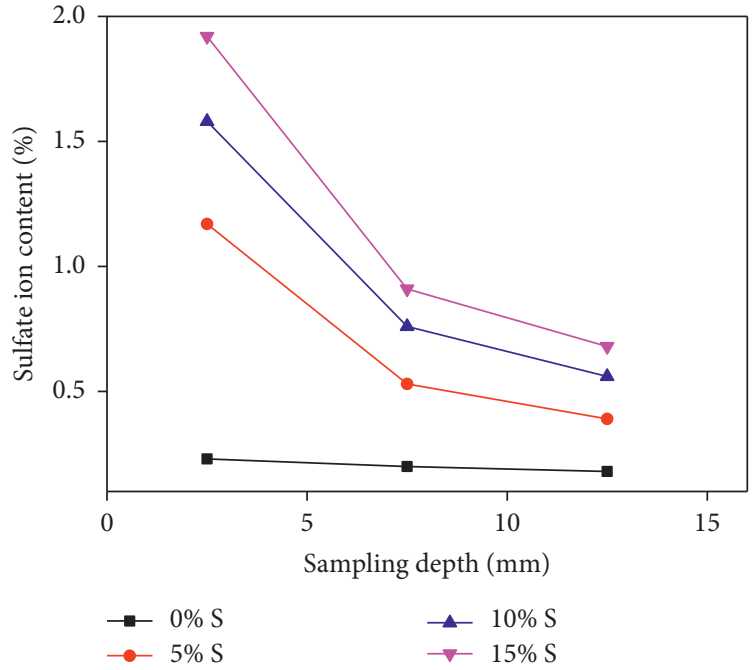

(b)

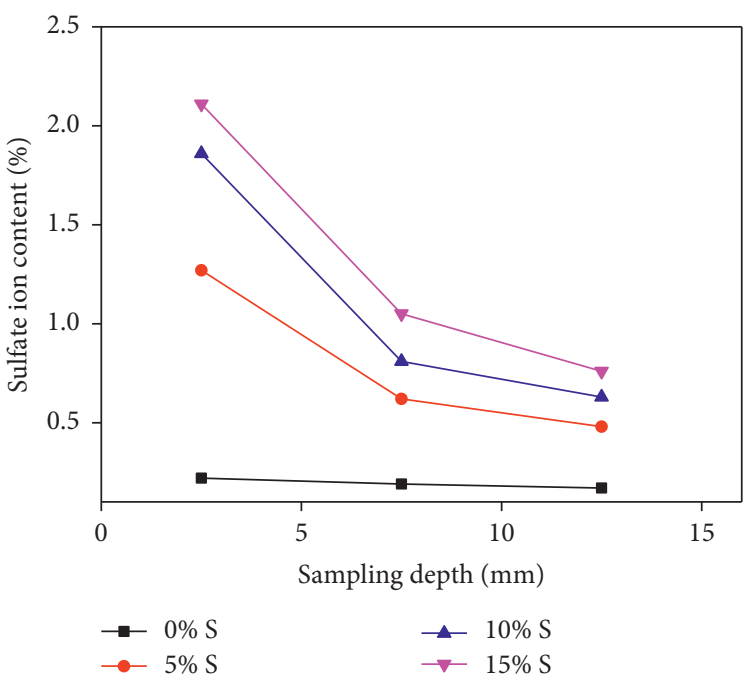

(c)

Figure 7: Sulfate ion contents at different depths of CGFB samples immersed in 0-15\% sodium sulfate solutions at the (a) third, (b) ninth, and (c) fifteenth drying-wetting cycles.

crystals had universal defects and grew irregularly near the ettringite, and the C-S-H gel decreased.

The XRD patterns of CGFB samples under sulfate attack of drying-wetting cycles are shown in Figure 10. At the third drying-wetting cycle, the intensity of the quartz diffraction peak was high, indicating that the cement particles were not completely hydrated and that there was not a large amount of fly ash involved in the reaction. In addition, the intensity of the gypsum diffraction peak was relatively low, indicating that most of the gypsum was converted to the ettringite during the erosion process. Additionally, no diffraction peak corresponding to mirabilite was found for the CGFB samples immersed in $0 \%$ sodium sulfate. The intensity of the C-S-H and ettringite peaks increased and that of the portlandite peak decreased in 5-15\% sodium sulfate solutions, which indicated that sulfate ions entering the paste reacted with hydration products to promote ettringite formation. Furthermore, the consumption of portlandite promoted the continuous hydration of cement particles, and more C-S-H was generated. At the fifteenth drying-wetting cycle, the intensities of the gypsum and quartz peaks were relatively low, indicating that the nonhydrated particles participated in the hydration reaction. Moreover, no mirabilite peak was found for the CGFB samples immersed in $0 \%$ sodium sulfate solution. In high concentration of salt solution, high intensities were observed for the mirabilite and ettringite peaks, and low intensities were observed for the portlandite and C-S-H peaks. This showed that the salt crystallized in the dry state, whereas the CGFB samples consumed portlandite to produce a large amount of ettringite in the wet state. 


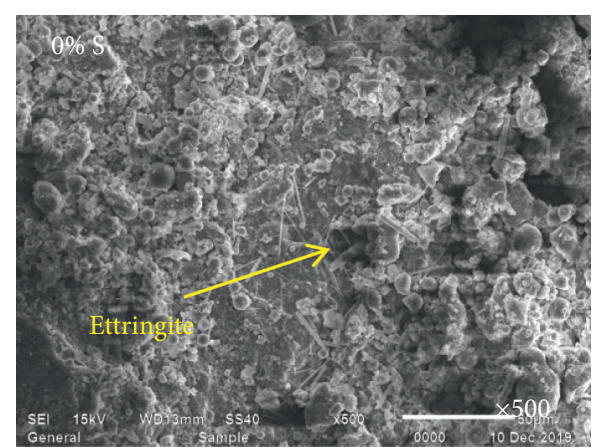

(a)

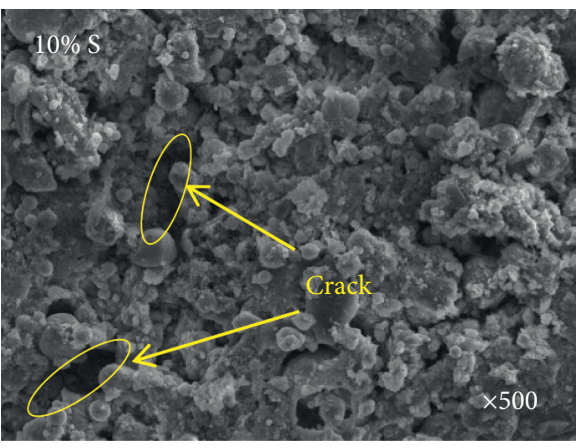

(c)

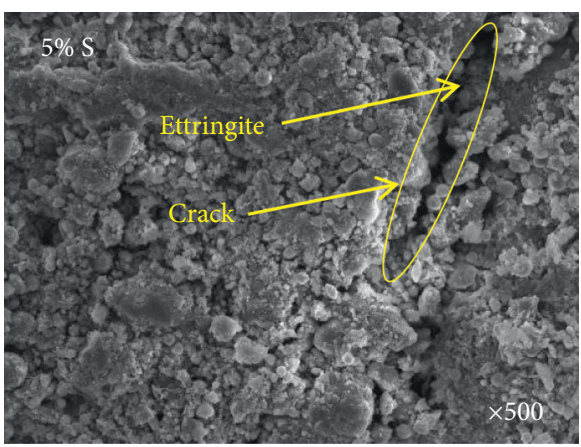

(b)

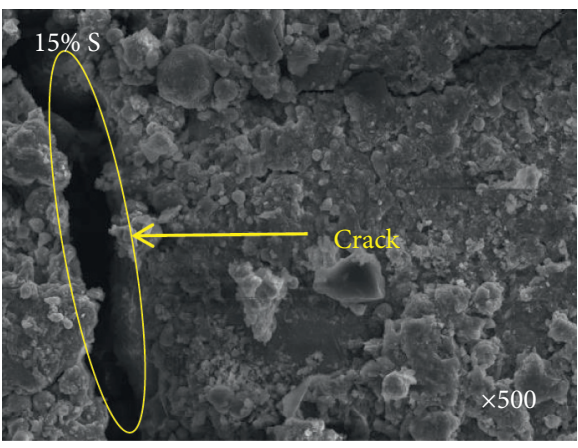

(d)

FIGURE 8: SEM images of the surface layers of CGFB samples immersed in $0-15 \%$ sodium sulfate solutions.
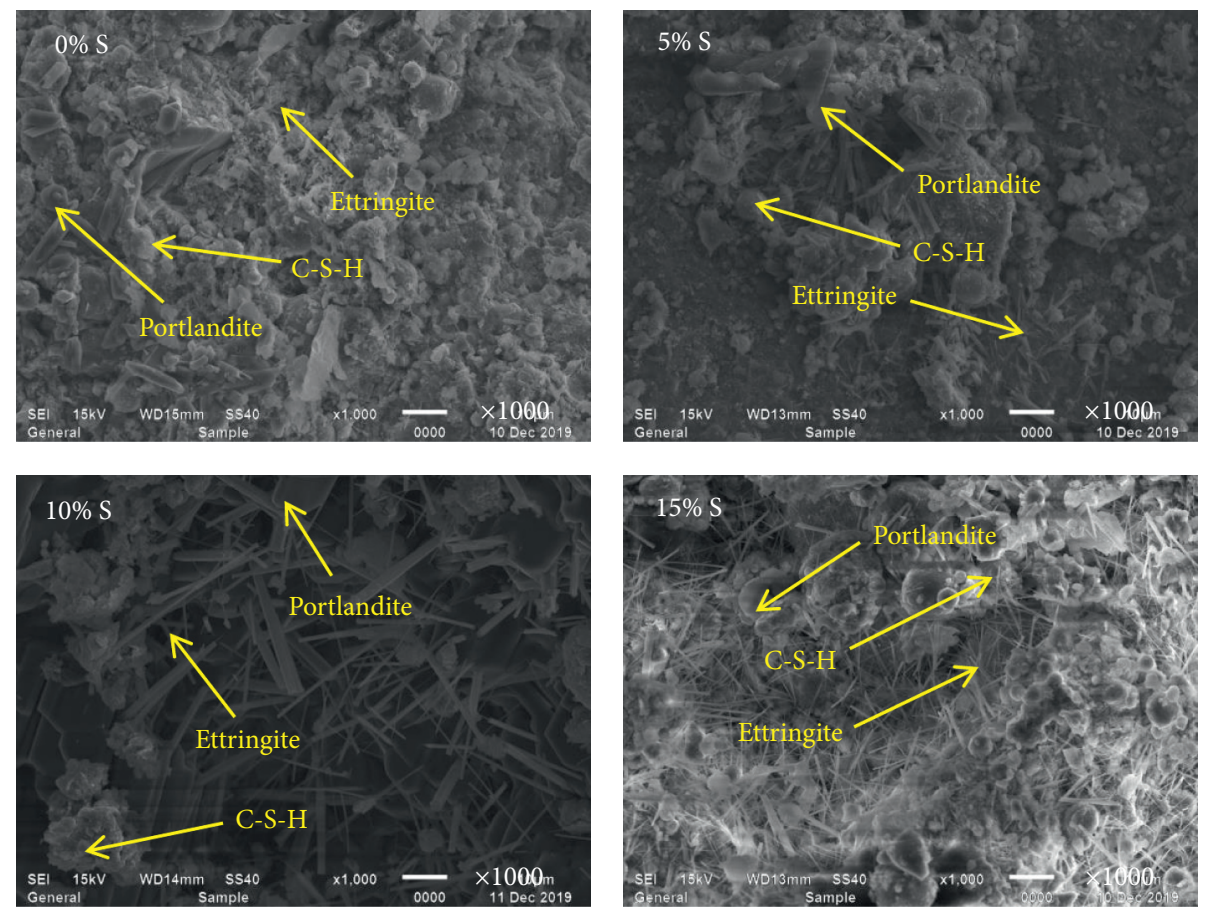

(a)

Figure 9: Continued. 

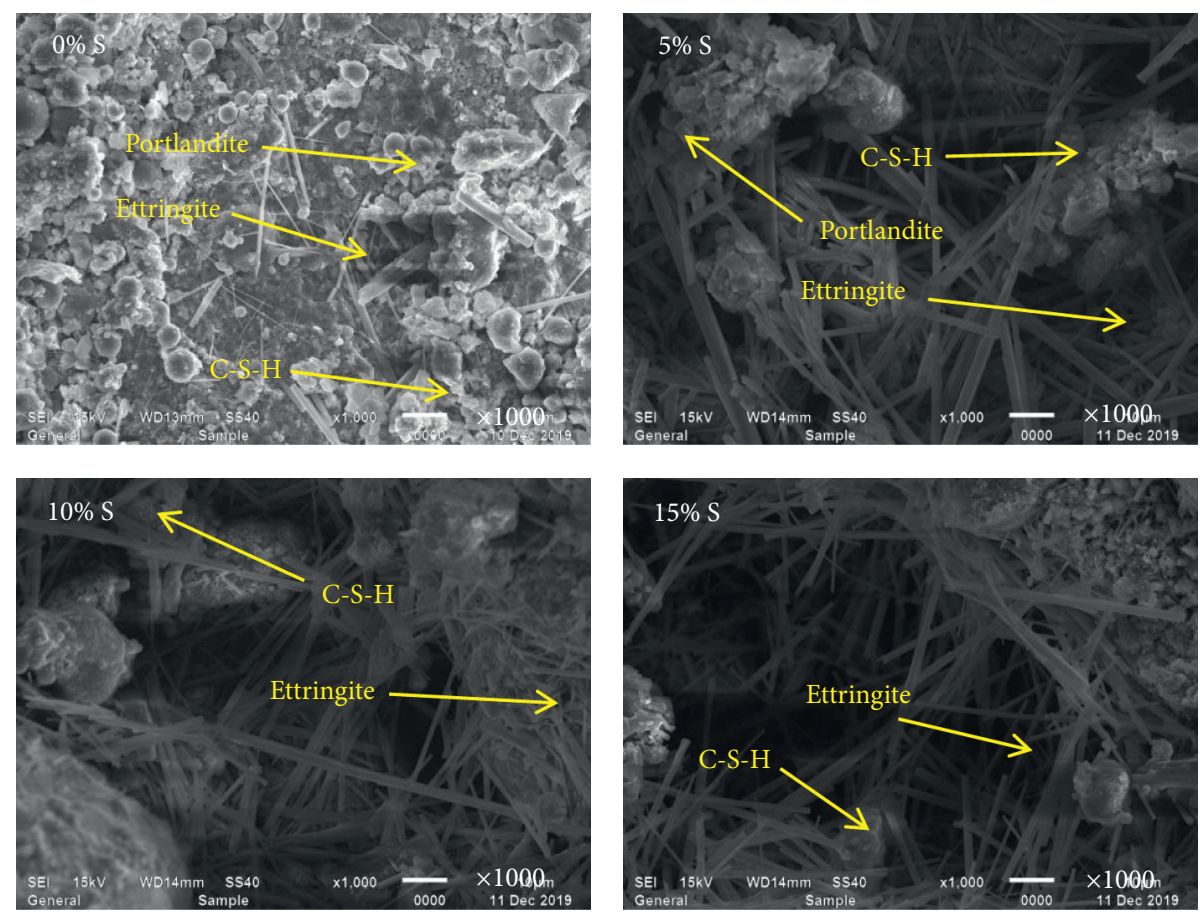

(b)

FIGURE 9: SEM images of CGFB samples immersed in 0-15\% sodium sulfate solutions at the (a) third and (b) fifteenth drying-wetting cycles.

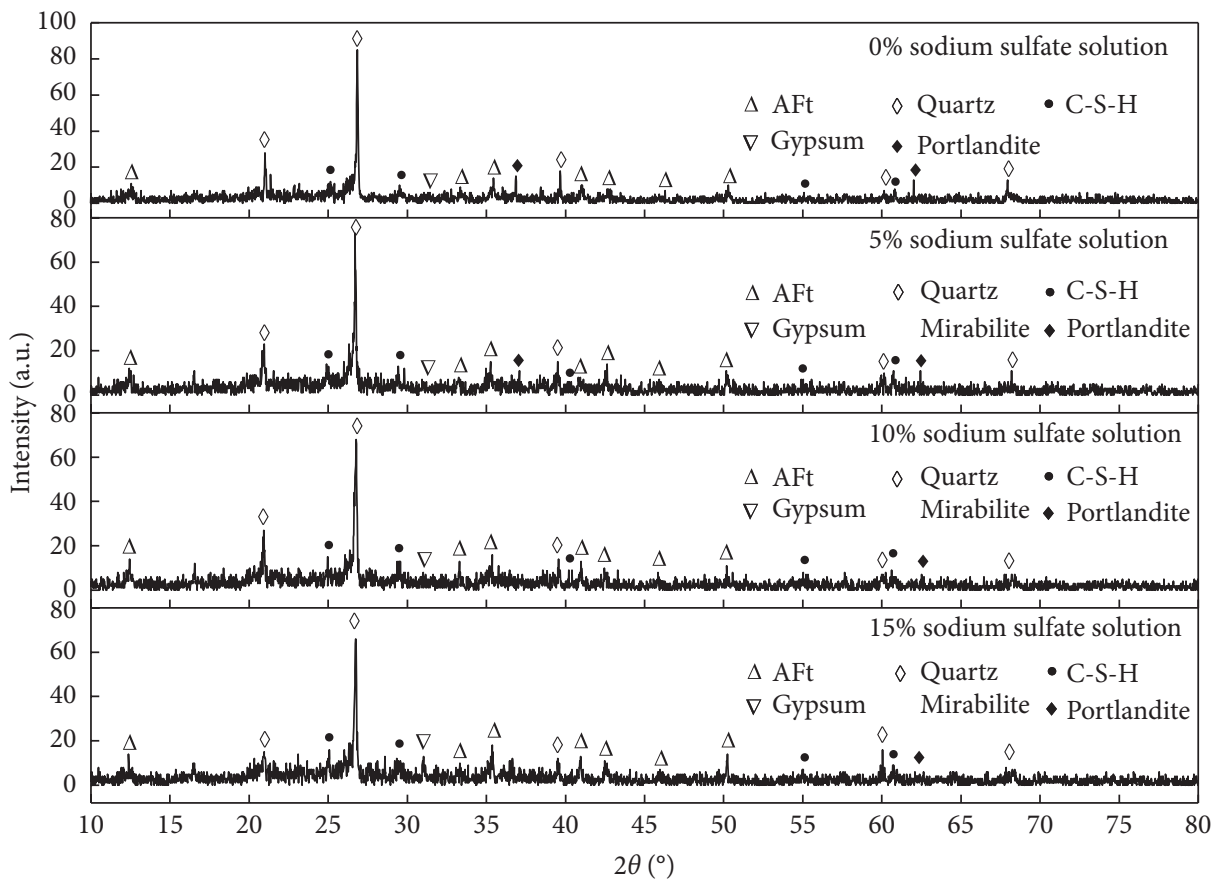

(a)

Figure 10: Continued. 


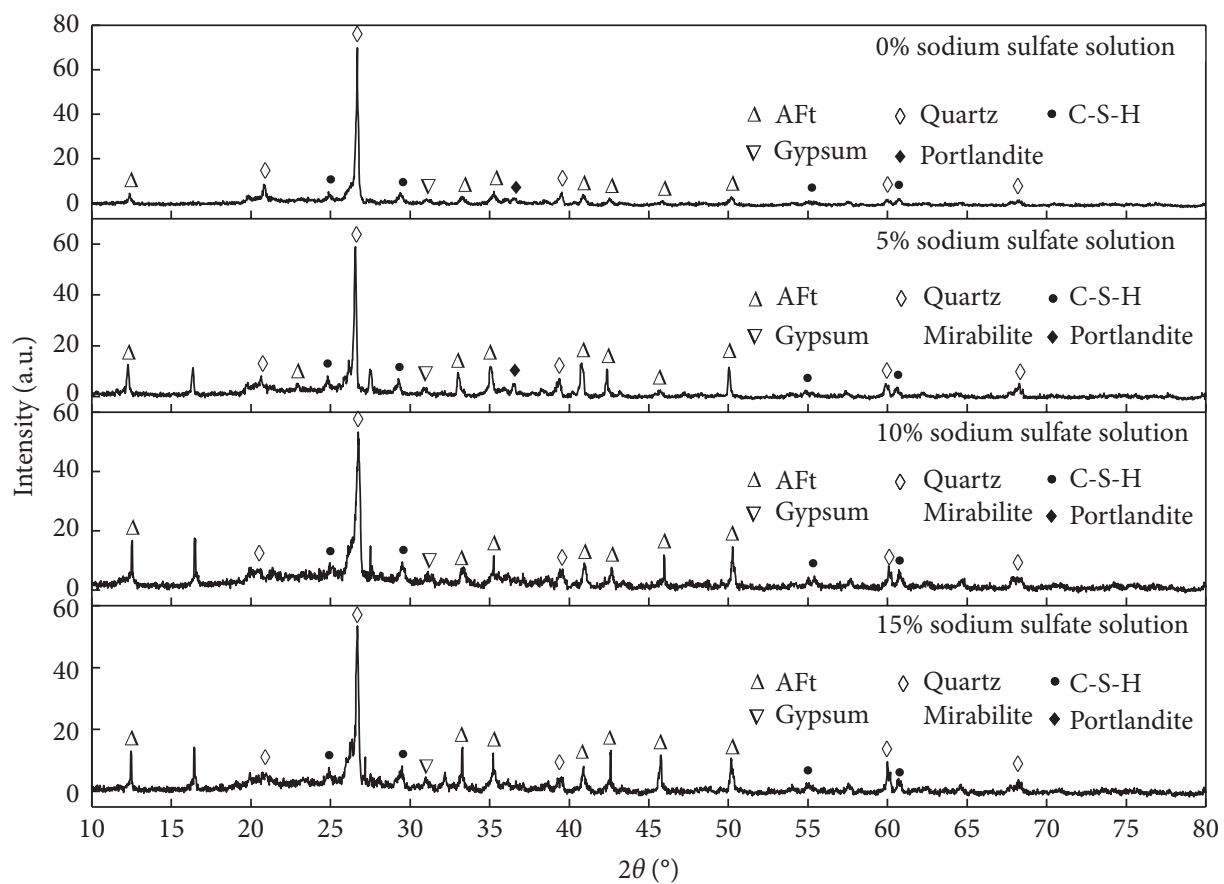

(b)

FIGURE 10: XRD patterns of CGFB samples immersed in 0-15\% sodium sulfate solutions at the (a) third and (b) fifteenth drying-wetting cycles.

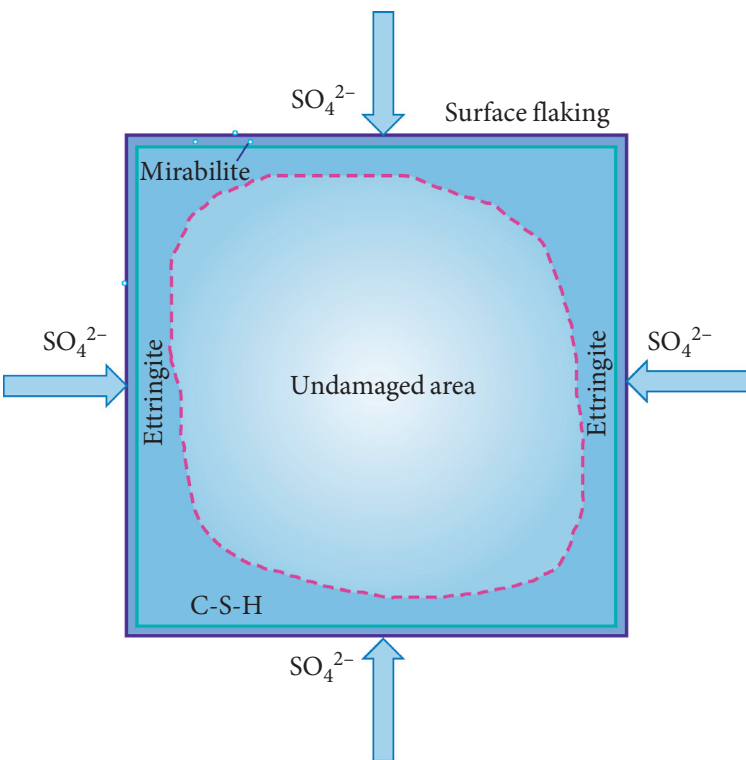

(a)

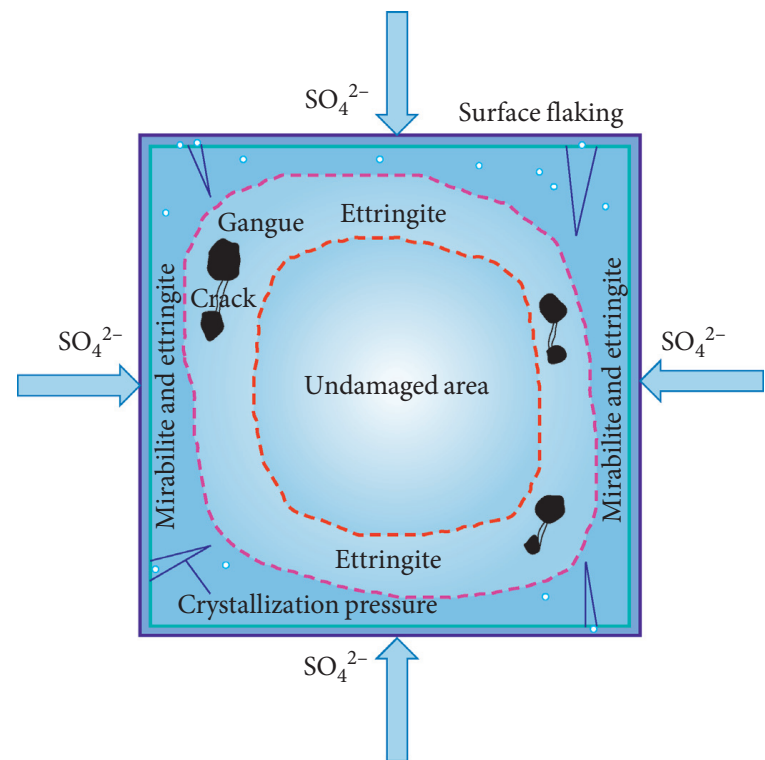

(b)

FIGURE 11: Damage process of CGFB samples under sulfate attack of drying-wetting cycles at the (a) first stage and (b) second stage.

3.3. Damage Process of CGFB Samples. As can be seen from Figure 11, the damage process of CGFB samples can be divided into two stages. In the early stage of corrosion, the surface layers of CGFB samples peel off because of the expansion and contraction from water absorption and loss. In addition, with high sulfate concentrations in solutions, 
sulfate ions adsorb to the surface and then diffuse into the CGFB samples through the pores and interfacial transition zones.

$$
\begin{gathered}
\mathrm{Na}_{2} \mathrm{SO}_{4}+\mathrm{Ca}(\mathrm{OH})_{2}+2 \mathrm{H}_{2} \mathrm{O} \longrightarrow \mathrm{CaSO}_{4} \cdot 2 \mathrm{H}_{2} \mathrm{O}+2 \mathrm{NaOH} \\
3 \mathrm{CaO} \cdot \mathrm{Al}_{2} \mathrm{O}_{3} \cdot 6 \mathrm{H}_{2} \mathrm{O}+3\left(\mathrm{CaSO}_{4} \cdot 2 \mathrm{H}_{2} \mathrm{O}\right)+20 \mathrm{H}_{2} \mathrm{O} \longrightarrow 3 \mathrm{CaO} \cdot \mathrm{Al}_{2} \mathrm{O}_{3} \cdot 3 \mathrm{CaSO}_{4} \cdot 32 \mathrm{H}_{2} \mathrm{O}
\end{gathered}
$$

The sulfate ions react with portlandite to form ettringite, which are subsequently held in the micropores and microcracks.

$$
\begin{aligned}
2\left(3 \mathrm{CaO} \cdot \mathrm{SiO}_{2}\right)+6 \mathrm{H}_{2} \mathrm{O} \longrightarrow & 3 \mathrm{CaO} \cdot 2 \mathrm{SiO}_{2} \cdot 3 \mathrm{H}_{2} \mathrm{O} \\
& +3 \mathrm{Ca}(\mathrm{OH})_{2} \\
2\left(2 \mathrm{CaO} \cdot \mathrm{SiO}_{2}\right)+4 \mathrm{H}_{2} \mathrm{O} \longrightarrow & 3 \mathrm{CaO} \cdot 2 \mathrm{SiO}_{2} \cdot 3 \mathrm{H}_{2} \mathrm{O} \\
& +\mathrm{Ca}(\mathrm{OH})_{2}
\end{aligned}
$$

Simultaneously, the consumption of portlandite promotes the hydration of cement particles, thus producing more cementitious substances.

$$
\begin{aligned}
\mathrm{Na}^{+}+\mathrm{SO}_{4}{ }^{2-}+10 \mathrm{H}_{2} \mathrm{O} & \longrightarrow \mathrm{Na}_{2} \mathrm{SO}_{4} \cdot 10 \mathrm{H}_{2} \mathrm{O} \\
& \longrightarrow \mathrm{Na}_{2} \mathrm{SO}_{4}+10 \mathrm{H}_{2} \mathrm{O}
\end{aligned}
$$

When the pores inside the CGFB samples are fully filled, with continued drying-wetting cycles and increment concentration of sulfate ions in the pore solution, the salt solution inside the paste easily reaches saturation and produces crystallization in the dry state. The crystals grow towards the pore walls, resulting in crystallization pressure between the crystal and walls. In addition, sodium sulfate crystals dissolve in the wet state, and the plastic damage is difficult to recover. The erosion ions enter into the CGFB samples to consume portlandite and produce expansive erosion products. This significantly reduces the adhesive properties of the internal CGFB structure and intensifies the internal damage of CGFB samples.

\section{Conclusions}

In this study, the macro performance and microstructures of cemented coal gangue-fly ash backfill (CGFB) under sulfate attack of drying-wetting cycles were investigated. The results elucidate the degradation regularity of CGFB under cyclic sulfate environment in coal mines.

When CGFB samples were under sulfate attack of drying-wetting cycles, the samples were damaged by salt crystallization in the dry state and attacked by expansive products in the wet state. In addition, the sulfate ion contents in CGFB samples increased with the sulfate concentrations and drying-wetting cycles and decreased with depth.

The damage of CGFB samples evolved from the surface to the inside. In the early stage of corrosion, sulfate ions adsorbed to the surface of the samples. For this stage, hydrated calcium silicate (C-S-H) and acicular ettringite were found in the CGFB samples. The samples immersed in $15 \%$ sodium sulfate solution led to denser internal structures and a more rapid increase of masses and strengths of CGFB samples. As the drying-wetting cycles continued, the sulfate ions invaded the interior of the CGFB samples, and the samples were constantly damaged by salt crystallization and dissolution. The quantity of prismatic ettringite increased, while that of acicular ettringite decreased in the samples immersed in $5-15 \%$ sodium sulfate solutions. At the fifteenth drying-wetting cycle, the higher the concentration of immersion solution was, the faster the masses and the strengths of CGFB samples decreased, and the more severe the surface spalling and the failure of CGFB samples were.

These conclusions are of great significance to further improve the adaptability of CGFB to the engineering environment in coal mines. Further research is required to explain the diffusion-reaction problem of sulfate ions and build the damage evolution model of CGFB under sulfate attack of drying-wetting cycles. More experimental studies are required to assess the durability of CGFB under mine water of drying-wetting cycles. In addition, the properties of CGFB with different types of cement and other pozzolanic materials, such as ceramic powder, silica fume, and red mud under this effect, should be studied.

\section{Data Availability}

The data used to support the findings of this study are included within the article.

\section{Conflicts of Interest}

The authors declare no conflicts of interest.

\section{Acknowledgments}

This work was supported by the National Key R\&D Programme (2018YFC0604704), the National Natural Science Foundation of China (51774194), the Shandong Provincial Natural Science Fund (ZR2018ZC0740), Taishan Scholars Project, SDUST Research Fund, Taishan Scholar Talent Team Support Plan for Advantaged and Unique Discipline Areas, and Project of Open Research Fund for Key Laboratories of Ministry of Education for Safe and Efficient Mining of Coal Mine (JYBSYS2019201). 


\section{References}

[1] X. F. Wang, C. G. Liu, S. J. Chen, L. Chen, K. Li, and N. Liu, "Impact of coal sector's de-capacity policy on coal price," Applied Energy, vol. 265, p. 114802, 2020.

[2] X. J. Zhu, G. L. Guo, H. Liu, and X. Y. Yang, "Investigating toppling failure mechanism of anti-dip layered slope due to excavation by physical modelling," Rock Mechanics and Rock Engineering, vol. 2020, pp. 1-22, 2020.

[3] X. Zhu, G. Guo, H. Liu, and X. Yang, "Surface subsidence prediction method of backfill-strip mining in coal mining," Bulletin of Engineering Geology and the Environment, vol. 78, no. 8, pp. 6235-6248, 2019.

[4] K. Ma, Y. X. Zhang, M. Y. Ruan, J. Guo, and T. Y. Chai, "Land subsidence in a coal mining area reduced soil fertility and led to soil degradation in arid and semi-arid regions," International Journal of Environmental Research and Public Health, vol. 16, no. 20, p. 3929, 2019.

[5] S. J. Chen, D. W. Yin, F. W. Cao, Y. Liu, and K. Q. Ren, "An overview of integrated surface subsidence-reducing technology in mining areas of China," Natural Hazards, vol. 81, no. 2, pp. 1129-1145, 2016.

[6] S. J. Chen, T. Q. Jiang, H. Y. Wang, F. Feng, D. W. Yin, and X. S. Li, "Influence of cyclic wetting-drying on the mechanical strength characteristics of coal samples: a laboratory-scale study," Energy Science \& Engineering, vol. 7, no. 6, pp. 3020-3037, 2019.

[7] Y. Liu, Y. J. Sun, and M. Wang, "Characteristics and pollution of mine water," Clean Coal Technology, vol. 3, pp. 83-86, 2007.

[8] Y. Liu, Y. Lu, C. X. Wang et al., "Effect of sulfate mine water on the durability of filling paste," International Journal of Green Energy, vol. 15, no. 13, pp. 864-873, 2018.

[9] B. Q. Cui, Y. Liu, H. Guo, Z. X. Liu, and Y. Lu, "Experimental study on the durability of fly ash-based filling paste in environments with different concentrations of sulfates," Advances in Materials Science and Engineering, vol. 2018, Article ID 4315345, 12 pages, 2018.

[10] P. Liu, Y. Chen, Z. W. Yu, and Z. H. Lu, "Effect of sulfate solution concentration on the deterioration mechanism and physical properties of concrete," Construction and Building Materials, vol. 227, Article ID 116641, 2019.

[11] Q. Sun, X. L. Li, X. Wei, and Q. W. Mu, "Study on creep property of paste filling materials under sulfate corrosion," Journal of Safety Science and Technology, vol. 11, no. 3, pp. 12-18, 2015.

[12] M. Fall and M. Pokharel, "Coupled effects of sulphate and temperature on the strength development of cemented tailings backfills: Portland cement-paste backfill," Cement and Concrete Composites, vol. 32, no. 10, pp. 819-828, 2010.

[13] M. Pokharel and M. Fall, "Combined influence of sulphate and temperature on the saturated hydraulic conductivity of hardened cemented paste backfill," Cement and Concrete Composites, vol. 38, pp. 21-28, 2013.

[14] C. Yu, W. Sun, and K. Scrivener, "Mechanism of expansion of mortars immersed in sodium sulfate solutions," Cement and Concrete Research, vol. 43, pp. 105-111, 2013.

[15] D. J. Thomas and J. Kinuthia, "Towards the development of smart sensors to prevent the failure of concrete infrastructure components," Journal of Failure Analysis and Prevention, vol. 17, no. 4, pp. 621-623, 2017.

[16] W. Y. Yao, Z. Q. Jin, S. Gao, and S. Y. Zhang, "Influence of temperature and chloride on chemical corrosion of concrete in sulphate," Journal of Shenyang University of Technology, vol. 37, no. 4, pp. 475-480, 2015.
[17] M. L. Nehdi, A. R. Suleiman, and A. M. Soliman, "Investigation of concrete exposed to dual sulfate attack," Cement and Concrete Research, vol. 64, pp. 42-53, 2014.

[18] M. F. Najjar, M. L. Nehdi, A. M. Soliman, and T. M. Azabi, "Damage mechanisms of two-stage concrete exposed to chemical and physical sulfate attack," Construction and Building Materials, vol. 137, pp. 141-152, 2017.

[19] Z. Q. Liu, D. H. Deng, G. D. Schutter, and Y. H. Liu, "Microanalysis of "sulfate salt weathering distress on concrete": II. Concrete," Journal of the Chinese Ceramic Society, vol. 40, no. 5, pp. 631-637, 2012.

[20] Z. Q. Liu, D. H. Deng, G. D. Schutter, and Z. W. Yu, "Chemical sulfate attack performance of partially exposed cement and cement + fly ash paste," Construction and Building Materials, vol. 28, no. 1, pp. 230-237, 2012.

[21] K. L. Ma, Y. J. Xie, G. C. Long, and D. L. Zhu, "Deterioration behaviors of sulfate crystallization attack on cement-based material," Journal of Central South University: Science and Technology, vol. 41, no. 1, pp. 303-309, 2010.

[22] J. M. Gao, Z. X. Yu, L. G. Song, T. X. Wang, and S. Wei, "Durability of concrete exposed to sulfate attack under flexural loading and drying-wetting cycles," Construction and Building Materials, vol. 39, pp. 33-38, 2013.

[23] W. Müllauer, R. E. Beddoe, and D. Heinz, "Sulfate attack expansion mechanisms," Cement and Concrete Research, vol. 52, pp. 208-215, 2013.

[24] J. H. Chen, S. B. Zhao, and J. T. Yao, "Thermal analysis of ettringite in concrete attacked by sodium sulfate in dry-wet cyclic environment," Journal of Basic Science and Engineering, vol. 18, no. 6, pp. 950-958, 2010.

[25] J. B. Wang, D. T. Niu, and Z. P. Song, "Damage layer thickness and formation mechanism of shotcrete with and without steel fiber under sulfate corrosion of dry-wet cycles by ultrasound plane testing method," Construction and Building Materials, vol. 123, pp. 346-356, 2016.

[26] R. D. Gao, S. B. Zhao, Q. B. Li, and J. H. Chen, "Experimental study of the deterioration mechanism of concrete under sulfate attack in wet-dry cycles," China Civil Engineering Journal, vol. 43, no. 2, pp. 48-54, 2010.

[27] Q. B. Yang and Q. R. Yang, "Effect of salt-crystallization of sodium sulfate on deterioration of concrete," Journal of the Chinese Ceramic Society, vol. 35, no. 7, pp. 877-880+885, 2007.

[28] Q. B. Yang and B. R. Zhu, "Deterioration of concrete due to action of salt crystallization," Journal of Building Materials, vol. 10, no. 4, pp. 392-396, 2007.

[29] J. Yuan, Y. Liu, Z. C. Tan, and B. K. Zhang, "Investigating the failure process of concrete under the coupled actions between sulfate attack and drying-wetting cycles by using X-ray CT," Construction and Building Materials, vol. 108, pp. 129-138, 2016.

[30] W. Tian, Z. Wang, and N. Han, "Study of meso-damage mechanism of concrete under sulfate attack," Journal of Disaster Prevention and Mitigation Engineering, vol. 39, no. 1, pp. 16-22+60, 2019.

[31] L. Jiang and D. T. Niu, "Study of deterioration of concrete exposed to different types of sulfate solutions under dryingwetting cycles," Construction and Building Materials, vol. 117, pp. 88-98, 2016.

[32] Y. J. Chen, J. M. Gao, L. P. Tang, and X. H. Li, "Resistance of concrete against combined attack of chloride and sulfate under drying-wetting cycles," Construction and Building Materials, vol. 106, pp. 650-658, 2016. 
[33] S. K. Cheng, Z. H. Shui, X. Gao et al., "Degradation mechanisms of Portland cement mortar under seawater attack and drying-wetting cycles," Construction and Building Materials, vol. 230, Article ID 116934, 2020.

[34] S. J. Chen, Z. W. Du, Z. Zhang, H. W. Zhang, Z. G. Xia, and F. Feng, "Effects of chloride on the early mechanical properties and microstructure of gangue-cemented paste backfill," Construction and Building Materials, vol. 235, Article ID 117504, 2020.

[35] S. J. Chen, Z. W. Du, Z. Zhang, D. W. Yin, F. Feng, and J. B. Ma, "Effects of red mud additions on gangue-cemented paste backfill properties," Powder Technology, vol. 367, pp. 833-840, 2020.

[36] B. Q. Cui, Macroscopic and Microcosmic Study on Performance Change of Filling Paste with Large Amount of Fly Ash in Sulfates Mine Water Environment, Shandong University of Science and Technology, Qingdao, China, 2019.

[37] J. Xu, A. Haque, W. M. Gong et al., "Experimental study on the bearing mechanisms of rock-socketed piles in soft rock based on micro X-ray CT analysis," Rock Mechanics and Rock Engineering, vol. 53, no. 8, pp. 3395-3416, 2020.

[38] R. D. Gao, Micro-macro Degradation Regularity of Sulfate Attack on Concrete under Complex Environments, Tsinghua University, Beijing, China, 2010.

[39] G. C. Shi, X. J. Yang, H. C. Yu, and C. Zhu, "Acoustic emission characteristics of creep fracture evolution in double-fracture fine sandstone under uniaxial compression," Engineering Fracture Mechanics, vol. 210, pp. 13-28, 2019.

[40] J. Xu, G. L. Dai, W. M. Gong, Q. Zhang, A. Haque, and R. P. Gamage, "A review of research on the shaft resistance of rock-socketed piles," Acta Geotechnica, vol. 1, 2020.

[41] S. J. Chen, D. W. Yin, N. Jiang, F. Wang, and Z. H. Zhao, "Mechanical properties of oil shale-coal composite samples," International Journal of Rock Mechanics and Mining Sciences, vol. 123, p. 104120, 2019.

[42] GB/T176-2017, Methods for Chemical Analysis of Cement, Chinese Standard Institution Press, China, 2017.

[43] Y. L. Wang, Study on Sulfate Attack Mechanism and Modifications of Concrete in West of China, Lanzhou Jiaotong University, Lanzhou, China, 2016.

[44] D. Z. Ren, D. S. Zhou, D. K. Liu, F. J. Dong, S. W. Ma, and H. Huang, "Formation mechanism of the Upper Triassic Yanchang Formation tight sandstone reservoir in Ordos Basin-Take Chang 6 reservoir in Jiyuan oil field as an example field as an example," Journal of Petroleum Science and Engineering, vol. 178, pp. 497-505, 2019.

[45] G. Feng, Y. Kang, X. C. Wang, Y. Q. Hu, and X. H. Li, "Investigation on the failure characteristics and fracture classification of shale under brazilian test conditions," Rock Mechanics and Rock Engineering, vol. 53, no. 7, pp. 33253340, 2020.

[46] H. Huang, T. Babadagli, X. Chen, H. Z. Li, and Y. M. Zhang, "Performance comparison of novel chemical agents for mitigating water-blocking problem in tight gas sands," in Proceedings of the SPE International Conference and Exhibition on Formation Damage Control, Lafayette, LA, USA, February 2020.

[47] G. Feng, X. C. Wang, M. Wang, and Y. Kang, "Experimental investigation of thermal cycling effect on fracture characteristics of granite in a geothermal-energy reservoir," Engineering Fracture Mechanics, vol. 235, Article ID 107180, 2020.

[48] F. Q. Ren, C. Zhu, and M. C. He, "Moment tensor analysis of acoustic emissions for cracking mechanisms during schist strain burst," Rock Mechanics and Rock Engineering, vol. 53, no. 1, pp. 153-170, 2020.

[49] H. Y. Pan, D. W. Yin, N. Jiang, and Z. G. Xia, "Crack initiation behaviors of granite specimens containing crossing-doubleflaws with different lengths under uniaxial loading," Advances in Civil Engineering, vol. 2020, Article ID 8871335, 13 pages, 2020.

[50] D. K. Liu, Z. L. Gu, R. X. Liang et al., "Impacts of pore-throat system on fractal characterization of tight sandstones," Geofluids, vol. 2020, Article ID 4941501, 17 pages, 2020.

[51] J. Wang, Y. Zhang, Z. Qin, S. G. Song, and P. Lin, “Analysis method of water inrush for tunnels with damaged waterresisting rock mass based on finite element method-smooth particle hydrodynamics coupling," Computers and Geotechnics, vol. 126, Article ID 103725, 2020. 